\title{
The Effects of Music during Warm-Up on Anaerobic Performance of Football Players
}

\author{
Sharifah Maimunah Syed Mud Puad ${ }^{1}$, Mazlan Ismail², Mohad Anizu Mohd Nor,", Wahidah Tumijan', \\ Ahmad Fikri Mohd Kassim ${ }^{3}$, Muhammad Amiruddin ${ }^{1}$ \\ ${ }^{1}$ Faculty of Sports Science and Recreation, Universiti Teknologi MARA, Seremban, 70300, Negeri Sembilan, Malaysia \\ ${ }^{2}$ Faculty of Sports Science and Recreation, Universiti Teknologi MARA, Shah Alam, 40450, Selangor, Malaysia \\ ${ }^{3}$ Faculty of Sports Science and Recreation, Universiti Teknologi MARA, Arau, 02600, Perlis, Malaysia
}

Received October 26, 2020; Revised November 20, 2020; Accepted December 30, 2020

\section{Cite This Paper in the following Citation Styles}

(a): [1] Sharifah Maimunah Syed Mud Puad, Mazlan Ismail, Mohad Anizu Mohd Nor, Wahidah Tumijan, Ahmad Fikri Mohd Kassim, Muhammad Amiruddin, "The Effects of Music during Warm-Up on Anaerobic Performance of Football Players," International Journal of Human Movement and Sports Sciences, Vol. 8, No. 6, pp. 477 - 482, 2020. DOI: 10.13189/saj.2020.080621.

(b): Sharifah Maimunah Syed Mud Puad, Mazlan Ismail, Mohad Anizu Mohd Nor, Wahidah Tumijan, Ahmad Fikri Mohd Kassim, Muhammad Amiruddin (2020). The Effects of Music during Warm-Up on Anaerobic Performance of Football Players. International Journal of Human Movement and Sports Sciences, 8(6), 477 - 482. DOI: 10.13189/saj.2020.080621.

Copyright@2020 by authors, all rights reserved. Authors agree that this article remains permanently open access under the terms of the Creative Commons Attribution License 4.0 International License

\begin{abstract}
Music has been used generally as a powerful tool to enhance an athlete's performance due to its psychological advantages. However, there has been a lack of data on the effects of music on anaerobic performance. This study aimed to investigate the effects of fast tempo music during warm up on short-term maximal performance of football players. This study involves twenty-four $(n=24)$ football players of DRB Hicom FC 2 from Kuala Lumpur Division 1 League. They need to undergo both tests which were with and without music. Heart rate before and after warming up, RPE, peak power, mean power and fatigue index were measured for this study. Mixed ANOVA was used to investigate the effect of music on heart rate while independent t-test was used on RPE, peak power, mean power, and fatigue index variables. The results showed that there is significant interaction of music on heart rate and fatigue index. In conclusion, there are significant effects of fast tempo music during warm up on short-term maximal performance in football players.
\end{abstract}

Keywords Music, Warm-up, Running Anaerobic Sprint Test, Football Players

\section{Introduction}

Music is a sound of art that expresses individual ideas and emotions with elements such as melody, rhythm, and harmony. Music also can be defined as a tone that can be sounded by one or many voices with and without instruments [1].

In the last decade, music is becoming an increasingly common feature in daily life as it is played during daily activities such as working, studying, and exercising. Music in general, plays a powerful social role in influencing cognitive functioning and stimulating deep emotions. Several studies have shown the positive effect music has on the individual's life experience [2, 3, 4].

The combination of music and exercise has received serious attention from the public and sportsmen. The use of music as an ergogenic aid is gaining popularity and becoming a trend in exercise and sport setting [3]. Many athletes or recreation individuals use music as a tool to increase exercise motivation and enhance athletic performance or experience [5]. Music has the capacity to lift spirits and motivation, capture attention, generate appropriate emotion to situation, regulate mood, elicit memories, increase work output, reduce psychological inhibitions, and promote rhythmic movement in sport and exercise performance [3], [4], [6]. 
Music comes in many different genres, types, and styles with different unique tempo and is based on how fast or slow of the beats. Tempo is also related to meter and is usually measured by bpm (beats per minute). There are about three music tempos which are slow (60-108 bpm), moderate (108-120) and fast tempo (120-168 bpm) [7]. Additionally, slow tempo music could be beneficial to those who require concentration and focus on their sport performance meanwhile fast upbeat music is useful to psych up and increase desired arousal during sporting activity [5]. It is suggested that the type of music and timing of usage must be suitable with the nature of the sports event [3], [4], [6].

Fast tempo music may give effect on heart rate response. Therefore, the usage of this music during warm up may facilitate the objective of warm up which is to raise the heart rate and muscle temperature [8]. Other than that, the nature of fast tempo and strong rhythmic music will help to stimulate the physiological target of warm up [9]. There are certain athletes who listen to upbeat tempo music when prepping for competition. It is suggested that music can cause dissociation, where the athlete will focus on the music and task rather than internal and external irrelevant cues that will disrupt athletic performance [9]. Sports such as football, sprinting, combat, or any other sports that involve anaerobic component in performance often listen to music during warmups. Previous researchers also found that fast upbeat music would be appropriate for fast power type movements [3], [10].

Fast tempo music also has been proved to improve anaerobic power [2], [3], [10]. The positive outcomes of this type of music are to reduce subjective perceived exertion and increased arousal resulting in higher ability of power production during anaerobic performance [3]. One of the methods to measure anaerobic power is by using Running Anaerobic Sprint Test (RAST). RAST consists of six sprints with 35 meters of each sprinting distance. It has a 10 second recovery between each of the sprints. As recommended by previous study where Running Anaerobic Sprint Test can measure the peak power, mean power, lower power, and a fatigue index [11].

Many studies investigate the effects of music on aerobic performance and most of them reported positive results [12], [15]. There has been a lack of studies that examine the effect of music on short-term maximal exercises [3], [4], [10], [16]. However, the effect of music on the anaerobic performance is not clear yet as shown by the inconsistent results. Moreover, it is noteworthy that some of the studies examined the effects of music while performing the task and these make the findings not applicable for athletes since they cannot listen to music while performing in real competition and games. Therefore, administering music during warm up may benefit athletes' performance more due to practical application in real athletic situations. The primary purpose of this study was to examine the effect of fast tempo music during warm up on short-term maximal anaerobic performance.

\section{Materials and Methods}

This study used quasi-experimental crossover design as all participants were switched to all treatment groups where the participants were used as his own control. In the present study, the group were classified into two which is no music (NMWU) and fast tempo music (MWU). Participants were unaware of the sequence of the treatments they received first. Purposive sampling is the sampling technique used in the present study.

Twenty-four football players from DRB Hicom FC 2 with mean age of $26.04 \pm 2.98$ years old and mean weight of $65.31 \pm 4.87 \mathrm{~kg}$ participated in this study. These football players train 2 days per week for an average of 4 hours on each day. All these athletes are free from any injuries and none on any medication. Written informed consent was obtained from all participants prior to the commencement of the study following detailed explanation of the experimental protocol, associated risks, and potential benefits of participation.

\subsection{Instrumentations}

Heart Rate Monitor Device. It is used to measure heart rate response during warm up with music intervention and control condition. Data from this variable reported the physiological response that reflects physical exertion of the participants during the warmup session.

Stopwatch. A stopwatch with a digital display was used to measure exercise and testing duration or timing.

Borg 6-20 Rating of Perceived Exertion (RPE). It is used to determine the subjective rate of physical activity intensity level. The Borg RPE is a numerical scale that ranges between 6 to 20, where 6 means "no exertion at all" which is no effect to the physical and psychological while 20 means "maximal exertion" where the individual has reached his or her maximum capacity or VO2max. A number from the scale of 6-20 was chosen to best describe the level of exertion during physical exercise [17].

Running Anaerobic Sprint Test (RAST). It consists of six sprints with 35 meters of each sprinting distance. It also has a 10 second recovery between each of the sprints. As it is an anaerobic performance test, it is to measure the peak power, mean power and a fatigue index (see Figure 1). 


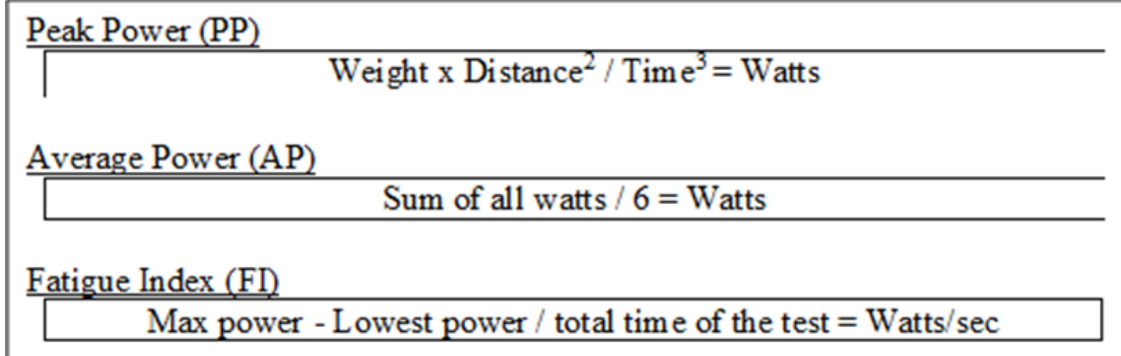

Figure 1. Equation for anaerobic performance calculation

Music. Fast tempo (>120bpm) and strong rhythm music which induce bodily action was used during the warm-up session. Music was played continuously from speakers.

\subsection{Procedure}

Written informed consent and ethical approval were obtained from all participants before the study. Following an initial familiarization session, participants attended the testing venue on two occasions separated by a week. Experimental testing was performed at the same hours in the same field terrain for the music conditions or for the non-music condition. By the same order, participants were tested for anaerobic power using the Running-based Anaerobic Sprint Test (RAST). The anaerobic output was calculated based on the time taken for each of the sprints.

Prior to the experimental testing, participants performed a 10 min warm-up either with (MWU) or without music (NMWU). During the warm-up, they were asked to perform slow jog until they reach 120 to $130 \mathrm{bpm}$ of their heart rate and maintain for 10 minutes. Rating of perceived exertion (RPE) was assessed using the 6 to 20-point Borg scale after the warm-up session. Immediately after warming up, participants proceed with the Running Anaerobic Sprint Test (RAST). It consists of six sprints with 35 meters of each sprinting distance and has 10 second recovery between each of the sprints. Peak power mean power and fatigue index were measured and calculated after they finish the short-term maximal exercise.

\section{Results}

Preliminary analyses were performed to ensure no violation of the assumptions of normality, linearity, and homoscedasticity. The results of repeated measures within between-interaction ANOVA revealed a significant interaction $(\mathrm{p}<.05)$ between experimental groups across experimental sessions for heart rate. Pairwise comparison shows that the music group reported desired heart rate response based on the mean differences. Table 1 presents the mean \pm SD value of the heart rate response.

The effects of music during warm up on rating perceived exertion (RPE), peak power, mean power and fatigue index of anaerobic performance were analyzed using independent t-test. Preliminary analyses were performed to ensure no violation of the assumptions of normality, linearity, and homoscedasticity. Table 2 shows the mean \pm $\mathrm{SD}$ values for the above variables. The findings of the independent t-test showed significant differences between music intervention group (MWU) and control group (NMWU) only for fatigue index $(\mathrm{p}<0.05)$. Music intervention group reported a lower fatigue index of anaerobic performance compared to the non-music control group.

Table 1. Mean $\pm \mathrm{SD}$ values of heart rate

\begin{tabular}{|c|c|c|c|c|}
\hline & \multicolumn{2}{|c|}{ Mean \pm SD } & \multirow{2}{*}{$\begin{array}{c}\text { Mean } \\
\text { difference }\end{array}$} & \multirow[b]{2}{*}{ Sig } \\
\hline & $\begin{array}{c}\text { Pre } \\
\text { (bpm) }\end{array}$ & $\begin{array}{l}\text { Post } \\
\text { (bpm) }\end{array}$ & & \\
\hline Music (MWU) & $\begin{array}{c}72.5 \pm \\
3.6\end{array}$ & $\begin{array}{c}129.7 \pm \\
4.0\end{array}$ & & \\
\hline $\begin{array}{c}\text { Control } \\
\text { (NMWU) }\end{array}$ & $\begin{array}{c}71.7 \pm \\
4.7\end{array}$ & $\begin{array}{c}115.3 \pm \\
5.7\end{array}$ & 13.6 & $0.01^{*}$ \\
\hline
\end{tabular}

*Significant difference between groups across experimental sessions

Table 2. Mean \pm SD values of RPE, peak power, mean power and fatigue index

\begin{tabular}{|c|c|c|c|c|c|}
\hline Variable & Group & $\mathbf{N}$ & $\begin{array}{l}\text { Mean } \pm \\
\text { SD }\end{array}$ & $\mathbf{t}$ & $\begin{array}{c}p \\
\text { value }\end{array}$ \\
\hline \multirow{2}{*}{ RPE } & MWU & 24 & $12.2 \pm 0.4$ & \multirow[b]{2}{*}{1.2} & \multirow[b]{2}{*}{0.52} \\
\hline & NMWU & 24 & $12.6 \pm 0.5$ & & \\
\hline \multirow{2}{*}{$\begin{array}{c}\text { Peak power } \\
\text { (Watt) }\end{array}$} & MWU & 24 & $\begin{array}{c}571.1 \pm \\
30.0\end{array}$ & \multirow[b]{2}{*}{1.4} & \multirow[b]{2}{*}{0.43} \\
\hline & NMWU & 24 & $\begin{array}{c}609.1 \pm \\
46.4\end{array}$ & & \\
\hline \multirow{2}{*}{$\begin{array}{l}\text { Mean power } \\
\text { (Watt) }\end{array}$} & MWU & 24 & $\begin{array}{c}516.5 \pm \\
29.1\end{array}$ & \multirow[b]{2}{*}{-0.2} & \multirow[b]{2}{*}{0.81} \\
\hline & NMWU & 24 & $\begin{array}{c}512.9 \pm \\
31.6\end{array}$ & & \\
\hline \multirow{2}{*}{$\begin{array}{c}\text { Fatigue index } \\
(\%)\end{array}$} & MWU & 24 & $3.3 \pm 0.5$ & \multirow[b]{2}{*}{3.2} & \multirow[b]{2}{*}{$0.01^{*}$} \\
\hline & NMWU & 24 & $5.5 \pm 1.3$ & & \\
\hline
\end{tabular}

*Significant difference between groups

MWU: Music Group

NMWU: Control Group

\section{Discussion}

The results have shown that there were significant 
changes in listening to music on heart rate response ( $p<$ $0.01)$ and fatigue index $(p<0.01)$ of anaerobic performance. Fast tempo music during warm up facilitates the elevation of heart rate to the desired target of $\sim 120 \mathrm{bpm}$ [18]. This indicates that this arousing music activates sympathetic activation faster [3, 4]. According to Atan, fast music affects heart rate during $40 \%$ to $60 \%$ intensity of VO2max [4]. Eliakim et al. also revealed higher mean heart rate in music group during warm up [5]. This also accords with our earlier observations, which showed that there were significant interactions for heart rate across different music tempos [19]. Previous researchers showed that fast tempo music does not significantly influence the heart rate in $75 \%$ VO2 max exercise intensity [20]. Thus, it proved that the influence of music on heart rate is effective during low intensity exercise as in warm up condition.

Findings of the present study revealed that there was no significant difference in rating perceived exertion (RPE) between music intervention group and no music group. This outcome is contrary to previous studies which have suggested that music is effective in reducing perceived level of exertion [10], [12]. The research conducted by Arazi, Asadi and Purabed also found that there was a significant difference in rating perceived exertion in well trained athletes during warm up [21]. As supported by previous researcher the sessions of higher exercise intensity may lead to significant changes on rating perceived exertion, but it may contrast for low intensity physical activity (below 60\% VO2max) [4]. This statement is consistent with findings from Yamashita et al. study that stated that listening a music during low intensity exercise such as jogging or walking or any other exercises that are low intensity will lead to no significant effect to rating perceived exertion but if with higher exercise intensity and longer duration, it will lead to the changes of higher RPE from time to time [22]. Due to subjective measures of RPE, there are many factors that may influence the outcomes. According to Chtourou and collogues, psychological status, individual and situation factors such as personality type, level of motivation, attention and exercise environment may influence the perceived rating exertion. RPE indicates perceived effort rate by the subjects during exercise performance [10].

There were no significant differences in peak power and mean power between intervention and control group during anaerobic performance measured by the Running Anaerobic Sprint Test (RAST). These results match those observed in earlier study that reported no significant difference between music and non-music groups [4]. In that study, 28 male subjects were required to undergo several experimental testing that required them to perform the RAST under 3 conditions (slow music, fast music, no music) on separate days. The researcher found no significant difference in power output, (peak power and mean power) between groups. Conversely, the present findings are contradictory to previous studies which reported a significant difference in peak power of anaerobic performance with music group showed significantly higher power output that without music group [13]. However, that research uses a different test which is Wingate anaerobic test (WAnT) compared to this research that used RAST test. As stated by previous researchers, there is a high correlation between Wingate anaerobic test and running anaerobic sprint test with 0.87 of reliability value [11]. However, higher peak power rates by Wingate test could be explained by the specific mechanical act of pedaling compared to the running activity [23].

The findings in this study also showed that there was no significant difference in mean power of anaerobic performance between music and control groups, respectively. As supported by previous study results when music had no significant effect on mean anaerobic power in men and women adolescence volleyball players [5]. Previous findings also found that music group showed no significant changes in mean power [24]. Additionally, Crust stated that exposure to music prior to exercise, to be specific during warm up, may not carry over to influence the whole performance duration [25]. The major influence of music occurred during the initial phase of the exercise task [5]. In contrast when previous study found that there was a significant difference in average power for active men in music condition [10]. However, the study used Wingate anaerobic test [10]. It has been suggested that the higher power output could be partly attributed to the subject's motivation level which had been stimulated with fast arousing music during the warm-up phase [10].

The fatigue index in the present study shows that there is a significant difference $(\mathrm{p}<0.05)$ of this variable between music and control groups. The music intervention group reported lower fatigue index compared to control condition. Low fatigue index indicates higher anaerobic capacity that reflects lower rate of power declines in anaerobic performance. Therefore, athletes in this condition can maintain power over a series of sprints in the RAST test. As supported by the previous report which music influences subjects' fatigue index to sustain longer anaerobic effort [23]. In contrast, previous researchers found that there were no significant effects on fatigue index during anaerobic cycling exercise with music intervention [5], [10]. But they measured peak power, mean power and fatigue index using Wingate cycle ergometer test in high intensity of $75 \%$ VO2max with and without music. It is suggested that the arousing upbeat music stimulates bodily action and increases motivation level at the warm-up phase which moderate down the sensation of fatigue during anaerobic performance.

\section{Conclusions}

The aim of this study was to determine the effect of listening to fast tempo music during warm up sessions on 
short term maximal sprinting performance in football players. Same music rhythm with the same tempo (166 bpm) was administered to all participants regardless of individual preference factor. Fast upbeat music selection was based on the mechanism that it increased levels of arousal and induced bodily action that facilitate warm up objectives [4], [5]. It is suggested that the usage of this type of upbeat music during warm up is more practical and more applicable to athletes since they only can listen to music before performing during real competition setting. The intent of this present study was to replicate the actual athletic sporting event environment.

In summary, the results of the study have proved that music can be used as ergogenic aids and legal method in enhancing anaerobic performance. Arousing fast tempo music during warm up had a significant effect on heart rate and fatigue index. This type of music provides physiological and psychological benefits to athletes. Thus, sport practitioners can incorporate fast upbeat music and warm up to achieve optimal anaerobic performance. Additional studies that measure other psychophysiological parameters conducted in different sport settings with different types of psychological intervention are needed to provide more concrete evidence of music effectiveness. In fact, a mental training session which includes tasks for different level of athletes should be planned for both team and individual sports [26 - 32]. The outcome of this study may be used to provide a better understanding of the differentiation among the nature of sports and guide further research.

\section{Acknowledgements}

We are very grateful to coaches and players for their cooperation and constructive suggestions to complete this research.

\section{REFERENCES}

[1] Nettl, Bruno. "The Art of Combining Tones: The Music Concept". The Study of Ethnomusicology. 2nd ed, University of Illinois Press, United States of America, 2005.

[2] Silva, A.G., Guida, H.L., Antonio, A.M., Marcomini, R.S. \& Fontes, M.G.G. An exploration of heart rate response to differing music rhythm and tempos, Complementary Therapies in Clinical Practices, Vol. 20, No. 2, 130-134, 2013.

[3] Arazi, H. Asadi, A., \& Purabed, M. Physiological and psychological responses to listening to music during warm up and circuit-type resistance exercise in strength trained men, Journal of Sports Medicine, 1-6, 2015.

[4] Atan, T. Effect of music on anaerobic exercise performance, Biology of Sport, Vol. 30. No. 1, 35-39, 2013.
[5] Eliakim, M., Meckel, Y., Nemet, D., Eliakim, A. The effect of music during warm-up on consecutive anaerobic performance in elite adolescent volleyball players, International Journal of Sports Medicine, Vol. 28, No. 4, 321-325, 2007.

[6] McCarty, R., Barrios-Choplin, B., Atkinson, M. \& Tomasino, D. The effects of music on mood, tension, and mental clarity, Alternatives Therapies, Vol. 4, No. 1, 75-84, 1998.

[7] Ting, C. Q. The effects of music tempo on memory performance using maintenance rehearsal and imagery, Sunway Academic Journal, Vol. 6, 114-132, 2006.

[8] Bishop, D. Performance changes following active warm up and how to structure the warmup, Sports Medicine, Vol. 33, No. 7, 483-498, 2003.

[9] Thakur, A. M., \& Yardi, S. S. Effect of different types of music on exercise performance in normal individuals, Indian Journal of Physiology and Pharmacology, Vol. 57, No. 4, 448-451, 2013.

[10] Chtourou, H., Jarraya, M., Aloui, A., Hammouda, O., \& Souissi, N. The effects of music during warm-up on anaerobic performances of young sprinters, Science and Sports, Vol. 27, No. 6, 85-88, 2012.

[11] Zagatto, A. M., Beck, W. R., \& Gobatto, C. A. Validity of the running anaerobic sprint test for assessing anaerobic power and predicting short-distance performances, Journal of Strength and Conditioning Research, Vol. 23, No, 6, 1820-1827, 2009.

[12] Karageorghis, C. I. Psychological, physiological, and ergogenic effects of music during swimming, Psychological of Sport and Exercise, Vol. 14, No. 4, 560 - 568, 2013.

[13] Jarraya, M., Chtourou, H., Aloui, A., Hammouda, O., Chamari, K., \& Chaouachi, A. The effects of music on high-intensity short-term exercise in well trained athletes, Asian Journal of Sports Medicine, Vol. 3, No. 4, 233-238, 2012.

[14] Waterhouse, J., Hudson, P., \& Edwards, B. Effects of music tempo upon submaximal cycling performance, Scandinavian Journal of Medicine \& Science in Sports, Vol. 20, No. 4, 662-669, 2010.

[15] Potteiger J.A., Schroeder J.M., Goffi K.L. Influence of music on ratings of perceived exertion during 20 minutes of moderate intensity exercise, Percept. Motor Skills, Vol. 91, 848-854, 2000.

[16] Pujol, T. J. \& Langen feld, M.E. Influence of music on Wingate anaerobic test performance, Perceptual and Motor Skills, Vol. 88, 292-296, 1999.

[17] Borg, G. "Perceived exertion as an indicator of somatic stress", Scand J Rehabil Med, Vol. 2, No. 2, 92-8, 1970.

[18] Horward, G.E., Blyth, C.S. \& Thornton, W.E. Effects of warm up on the heart rate during exercise, Journal of Health, Physical Education and Recreation, Vol. 37. No. 3, 360-367, 2013.

[19] Edworthy J., Waring H. The effects of music tempo and loudness level on treadmill exercise, Ergonomics, Vol. 49, No. 15, 1597-1610, 2006. 
[20] Schwartz, S. E., Fernhall, B., Plowman, S.A. Effects of music on exercise performance, Journal of Cardiopulmonary Rehabilitation, Vol. 10, 312-316, 1990.

[21] Arazi, H. Asadi, A., \& Purabed, M. Physiological and psychological responses to listening to music during warm up and circuit-type resistance exercise in strength trained men, Journal of Sports Medicine, 1-6, 2015.

[22] Yamashita S., Iwai K., Akimoto T., Sugawara J., Kono I. Effects of music during exercise on RPE, heart rate and the autonomic nervous system, Journal Sports Medicine Physical Fitness, Vol. 46, No. 3, 425-430, 2006.

[23] Zacharogiannis E, Paradisis G, Tziortzis S. An evaluation of tests of anaerobic power and capacity, Med Sci Sports Exerc, Vol. 36, 116, 2004.

[24] Burgees, K., Holt, T., Munro, S., \& Swinton, P. Reliability, and validity of the running anaerobic sprint test (RAST) in soccer players, Journal of Trainology, Vol. 5, No. 2, 24-29, 2016.

[25] Crust L. Carry-over effects of music in an isometric muscular endurance task, Perceptual Motor Skills, Vol. 98, No. 3, 985-991, 2004.

[26] Mazlan, I. Practice in mind: help to improve golf putting from the hardest distance, International Journal of Enhanced Research in Education Development, Vol. 2, No. 2, 7 - 12, 2014.
[27] Mazlan, I. The idea of using PIM training program to improve self-efficacy of the golfers, International Journal of Enhanced Research in Education Development, Vol. 3, No. 2, 2320-8708, 2015.

[28] Mazlan, I. Effectiveness of "PIM" Training on Putting Performance and Pre-Competitive Anxiety of the Golfers, International Journal of Golf Science, Vol. 5, No. 1, 26-37, 2016.

[29] Mohd Fared, Y., Mazlan, I., \& Afizan, A. The idea of using practice in mind training program for rugby players to improve anxiety and kicking performance, International Journal of Sports Science, Vol. 6, No. 2, 70 - 75, 2016.

[30] Nur Asmidar A. H., Mazlan, I., \& S.M.P. Sharifah Maimunah. The Idea of Using Systematic Imagery Physical Practice on Netball Jump Shot Performance, International Journal of Sports Science, Vol. 6, No. 4, 159 162, 2016.

[31] Afifah, A., \& Mazlan, I. The effect of practice in mind (pim) training on jumping performance of high jumpers, International Journal of Sports Science, Vol. 8, No. 1, 3842, 2018.

[32] Ismail, M., \& Ismail, A.N. The effects of practice in mind (pim) training on performance strategies used by professional university football players, Pertanika Journal of Social Sciences and Humanities, Vol. 27, No. 2, 1357 1365, 2019 